\title{
OS COMPUTADORES NO BRASIL E O DESPREPARO DE SEUS USUÁRIOS.
}

\author{
LIMA, Jorge Luis Silvério de ${ }^{1}$ \\ SILVA, Regina Célia Marques Freitas ${ }^{2}$
}

Recebido em: $2008-10-13$

Aprovado em: 2009-03-09

ISSUE DOI: 10.3738/1982.2278.145

RESUMO: Discute a informática no Brasil e sua relação com os usuários domésticos de computadores. Apresenta dados sobre seu despreparo técnico, relaciona os perigos que esse despreparo pode ocasionar ao usuário e sua máquina. Fornece dados sobre o número de computadores no país e a tendência cada vez maior de crescimento nas vendas de hardware e o aumento no número de usuários. Coloca em foco uma discussão sobre o termo inclusão digital, questionando seu significado técnico e social. Apresenta estatística sobre o uso de sistemas operacionais no Brasil e no mundo. Demonstra os problemas mais comuns que podem ocorrer no sistema Windows e enfoca o próprio usuário como fonte de solução para esses problemas.

PALAVRAS-CHAVE: Inclusão digital. Despreparo. Usuário. Informação. Segurança. solução

SUMMARY: It emphasizes the computer science in Brazil and its relation with the computer users. It presents data about its low technical knowledge in the country, relates the dangers that this lack of knowledge may cause for the user and its machine. It gives information on the number of computers in Brazil and the tendency of the hardware sales to grow and the growing in the number of users. What is in the spotlight here is the discourse about the term digital inclusion, questioning its technical and social meaning. Presents the odds of the use of Operational Systems in Brazil and the world. It Demonstrates the most common problems that can happen on Windows systems and focuses the user itself as a source of solution for this problems.

KEYWORDS: Digital Inclusion. low technical knowledge. User. Information. Security. Solution

\section{INTRODUÇÃO}

A criação da informática e suas ferramentas facilitaram diversos setores econômicos, sociais e a vida de muitas pessoas. Porém a população está preparada para utilizar plenamente esses recursos?

\footnotetext{
1 Graduando em Sistemas de Informação

2 Coordenadora do curso de Sistemas de Informação FE/FAFRAM
} 
Segundo dados do Centro de Tecnologia da Informação da Fundação Getúlio Vargas de São Paulo, atualmente existem 40 milhões de computadores em uso no país. Apenas no ano de 2006, foram vendidos 7,4 milhões de computadores. "Os valores e estudos divulgados comprovam um crescente processo de informatização das empresas e da sociedade..."(MEIRELLES, 2007).

Isso nos levanta uma questão sobre inclusão digital, porém como analisar se determinado nicho de pessoas está incluído digitalmente? O simples uso do computador atende a esses requisitos? "A inclusão digital basicamente é a iniciativa de fazer com que a sociedade obtenha conhecimento mínimo para utilizar os recursos da tecnologia da informação e de comunicação (TIC), bem como ter e utilizar os recursos físicos, tais como os computadores com acesso à internet" (TOSHIO, 2007).

Percebemos que a inclusão digital não está sendo tratada de forma correta. A grande maioria dos usuários domésticos de computadores possuem apenas conhecimentos básicos, como o sistema operacional Windows e o pacote Office $e^{3}$. Fazendo uma analogia, podemos dizer que são apenas motoristas, que não entendem muito bem como seu veículo funciona e quando ele apresenta problemas, o levam ao mecânico. Contudo, a grande maioria dos motoristas sabe pelo menos 'trocar um pneu' e tem conceitos mais esclarecidos sobre o sistema de funcionamento de seu veículo, pois passaram por um preparo na auto-escola. $\mathrm{O}$ usuário de computador nem sempre teve disponível um mínimo preparo técnico ou informações que o permitissem 'trocar o pneu de seu computador'.

\section{PERIGOS DA FALTA DE INFORMAÇÃO}

A falta de informação, na maioria das vezes, é a maior inimiga do usuário de computador. Com a popularização da Internet, diversas ameaças colocam em risco o usuário, tais como: vírus, spywares ${ }^{4}$ phishing $^{5}$, entre outras.

\footnotetext{
Phishing é um tipo de fraude electrónica criada para roubar informações valiosas e particulares. Num phishing (também conhecido como phishing scam, ou apenas scam), uma pessoa malintencionada envia uma mensagem electrónica, geralmente um e-mail, recado no site Orkut ("scrap"), entre outros exemplos. Utilizando de pretextos falsos, tenta enganar o receptor da mensagem e induzi-lo a fornecer informações sensíveis (números de cartões de crédito, senhas, dados de contas bancárias, entre outras) ou transferir e
}

3 Pacote de software que inclui o Word, Excel e Power Point

4 Programas que roubam informações pessoais para fins ilícitos.

5 Técnica de trapaça usada para remeter o usuário à uma pagina web falsa, tipo site bancário para pegar seus dados de acesso. 
executar e ficheiros que permitam o roubo futuro de informações ou o acesso não autorizado ao sistema da vítima. (BASTOS, 2007)

Esse tipo de técnica está sendo muito utilizado atualmente e, ao contrário de vírus e outros tipos de pragas virtuais, o alvo não é o micro da pessoa e sim seu bolso. A informação é a melhor forma de prevenir o usuário de ser lesado por esse tipo de fraude, porém segundo uma pesquisa efetuada pela América Online em conjunto com a Aliança Nacional para a Segurança Cibernética datada de dezembro de 2005:

\footnotetext{
Um em cada quatro internautas está exposto todos os meses a ameaças como mensagens eletrônicas falsas que tentam roubar informações pessoais e não está preparado para enfrentá-las"...70\% dos usuários não suspeitavam que estas mensagens eram falsas, e que vinham de fontes ilegítimas. (TERRA TECNOLOGIA, 2005).
}

Segundo dados dessa pesquisa, $74 \%$ dos entrevistados utilizava o computador para fazer transações delicadas via Internet, como transações bancárias e compras online. "As pessoas têm um falso sentimento de segurança" (PLATT, 2005).

A falsa sensação de segurança, a idéia de 'que comigo esse tipo de coisa não acontece', é um fator perigoso que contribui anualmente para o aumento das estatísticas de danos causados por pragas e ataques virtuais. Segundo o estudo, $81 \%$ dos computadores não possuíam softwares de proteção considerados mínimos, como um bom antivírus atualizado, proteção contra spywares e firewall $^{6}$ funcionando corretamente.

Ainda assim $83 \%$ dos entrevistados se consideravam estar a salvo dessas ameaças.

\section{O USUÁRIO RESOLVENDO SEUS PRÓPRIOS PROBLEMAS}

O sistema operacional Microsoft Windows domina o mercado mundial de sistemas operacionais. "Uma pesquisa realizada em julho do ano passado, pela Network Computing Magazine, mostrou que $90 \%$ dos computadores empresariais rodam Windows. No ambiente doméstico, analistas da indústria calculam a mesma média"(REBELO, 2006).

Segundo o W3Counter (2007), site especializado em levantamentos de estatísticas sobre uso de softwares, a versão XP, representa $83 \%$ dos sistemas operacionais utilizados atualmente, conforme pode ser visto na Figura 1.

6 Software de proteção contra acesso remoto não autorizado. 


\begin{tabular}{|llr|}
\hline \multicolumn{2}{|c|}{ Operating Systems } \\
\hline 1 & Windows XP & $83.36 \%$ \\
\hline 2 & Windows 2000 & $3.87 \%$ \\
\hline 3 & Mac OSX & $3.71 \%$ \\
\hline 4 & Windows Vista & $3.66 \%$ \\
\hline 5 & Linux & $1.37 \%$ \\
\hline 6 & Windows 98 & $1.31 \%$ \\
\hline 7 & Windows 2003 & $0.69 \%$ \\
\hline 8 & Windows ME & $0.46 \%$ \\
\hline 9 & Windows NT & $0.06 \%$ \\
\hline 10 & Mac PowerPC & $0.03 \%$ \\
\hline
\end{tabular}

FIGURA 1 - Estatística sobre o uso dos Sistemas Operacionais no mundo. Disponível em: http://www.w3counter.com/globalstats.php

O Windows é um sistema simples, de fácil aprendizado e uso. Porém resolver problemas que podem ocorrer no sistema requer pequenos conhecimentos específicos, fato que na maioria das vezes leva o usuário a recorrer à assistência técnica. Alguns desses problemas poderiam ser resolvidos pelos próprios usuários, se eles tivessem informações simples e as aplicassem, tais como: manter o sistema atualizado, usar bons softwares de proteção e desfragmentar periodicamente o disco rígido evitando a perda de desempenho do sistema.

Esses erros no sistema podem ocorrer devido a vários fatores tais como: desligamento errado, corrupção de arquivos por vírus, entre outros. Estes são exemplos de problemas que o próprio usuário poderia resolver. Usando um bom software antivírus $^{7}$, atualizado e, principalmente mantendo-o ativo. De nada adianta ter um antivírus instalado e o usuário fechá-lo por qualquer que seja o motivo. Evitar abrir arquivos suspeitos principalmente recebidos por e-mail de remetente desconhecido.

Problemas causados por mau desligamento do sistema, geralmente afetam o setor de inicialização do Windows, corrompendo arquivos e impedindo que o sistema inicie corretamente, por tal motivo é sempre recomendado desligar o sistema no menu iniciar, desligar. Possuindo o disco de instalação do sistema, na grande maioria das vezes esses problemas podem ser corrigidos, pois, existem ferramentas de reparo disponíveis no próprio disco de instalação, que geralmente são desconhecidas pelo usuário.

7 Programa que protege o computador contra virus e outros tipos de softwares maliciosos. 


\section{CONCLUSÃO}

A informação como base do conhecimento é um fator decisivo para inclusão digital. Cabe aos profissionais de informática a criação de meios que facilitem sua distribuição e acesso a todos.

Dispondo de conhecimentos básicos de uso e manutenção do sistema, as chamadas à assistência técnica ocorrerão com menor freqüência, sendo somente necessárias se houverem problemas específicos que requeiram mão de obra especializada. A ferramenta de auxílio ao usuário iniciante de computador, desenvolvida pelo autor, como trabalho de conclusão de curso da Faculdade Francisco Maeda, oferece dicas e informações uteis ao usuário para resolver problemas que ocorram em seu cotidiano. Desta forma o usuário não somente economiza dinheiro, como também utiliza de forma mais plena sua ferramenta de trabalho, estudo, diversão e lazer, o computador.

\section{REFERÊNCIAS}

BASTOS, L. Extensão Firefox - 10 extensões anti-phishing. 2007. Disponível em: $<$ http://www.programaslivres.net/?p=870>. Acesso em 20 set 2007.

MEIRELLES, F. S. Empresas Gastam 5,5\% do faturamento liquido em TI. 2007. Disponível

em: <http://www.telecentros.desenvolvimento.gov.br/sitio/destaques/destaque.php?sq_n oticia=196>. Acesso em 20 set 2007.

PLATT, T. Usuários não estão preparados para as ameaças na web. 2005. Disponível em:

$<$ http://tecnologia.terra.com.br/interna/0,,OI788506-EI4805,00.html> Acesso em 20 set 2007.

REBELO, P. Windows 98 chega ao fim (oficialmente) no Brasil. 2006. Disponível em: <http://www.pcsos.com.br/news.php?cid=3\&nid=70>. Acesso em 20 set 2007

TOSHIO, A.. A inclusão digital no Brasil. 2007.Disponível em:

<http://www.imasters.com.br/artigo/5004/gerencia/a_inclusao_digital_no_brasil/>. Acesso em 20 set 2007.

TERRA TECNOLOGIA.Usuários não estão preparados para as ameaças na web. 2005. Disponível em: < http://tecnologia.terra.com.br/interna/0,,OI788506EI4805,00.html> Acesso em 20 set 2007. 
